\title{
Praxiologia motriz: novas proposições para o treinamento dos jogos esportivos coletivos
}

\author{
Bruno Minuzzi Lanes ${ }^{1}$ \\ Cesar Vieira Marques filho² \\ Raquel Valente de Oliveira ${ }^{3}$ \\ João Francisco Magno Ribas ${ }^{4}$
}

\section{RESUMO}

O processo de treinamento dos Jogos Esportivos Coletivos (JECs) vem sofrendo críticas pela forma como é materializado, pois o treinador nem sempre possui argumentos e métodos de ensino que condizem com o que vem sendo defendido na bibliografia científica. Ainda se percebe um treinamento descontextualizado da lógica do jogo, acreditando que o aperfeiçoamento técnico irá suprir todos os elementos que compõem os JECs. Em contrapartida, a Praxiologia Motriz apresenta-se como uma importante teoria que poderá nortear a prática pedagógica do treinador, na qual sistematiza a lógica interna dessas modalidades. Assim, realizou-se uma pesquisa bibliográfica e exploratória que objetivou analisar as implicações dos conceitos da Praxiologia Motriz no processo de treinamento dos JECs. A partir da Praxiologia Motriz e de seus elementos, apresentou-se novos pressupostos para o treinamento com o intuito de auxiliar os treinadores a materializar sua prática pedagógica na busca por um desempenho mais eficaz neste processo.

Palavras-chave: Jogos esportivos coletivos. Treinamento. Praxiologia motriz

1 Mestrando do Programa de Pós Graduação em Educação Física do Centro de Educação Física e Desportos da Universidade Federal de Santa Maria (PPGEF/UFSM). Santa Maria/Rio Grande do Sul, Brasil.

E-mail: brunolanes10@hotmail.com

2 Mestre pelo Programa de Pós Graduação em Educação Física do Centro de Educação Física e Desportos da Universidade Federal de Santa Maria (PPGEF/UFSM). Santa Maria/Rio Grande do Sul, Brasil.

E-mail: cesarvmf@hotmail.com

3 Acadêmica do Curso de Educação Física Licenciatura do Centro de Educação Física e Desportos da Universidade Federal de Santa Maria (UFSM). Santa Maria/Rio Grande do Sul, Brasil. E-mail: raquelvvallente@hotmail.com

4 Doutor em Educação Física. Professor associado do Departamento de Desportos Coletivos, do Centro de Educação Física e Desportos da Universidade Federal de Santa Maria (UFSM). Santa Maria/Rio Grande do Sul, Brasil. E-mail: ribasjfm@hotmail.com

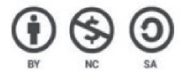




\title{
Motor praxeology: new propositions for team sports training
}

\begin{abstract}
The process of Team Sports Training has been suffering reviews due to way as is materialized, because the coach does not always have arguments and teaching methods that combine with what in scientific literature has defended. We still perceives a training decontextualized of game logic, believing that the technical improvement will supply all elements, which composes the Team Sports. On the other hand, the Motor Praxeology presents itself as an important theory that will can guide the coach's teaching practice, in which he systematises the internal logic of these modalities. This way, we realized a bibliography and exploratory research with the objective to analyse the implications of Motor Praxeology concepts in Team Sport training process. From Motor Praxeology and its elements, we presented new assumptions to Training with the aim of helping the coaches materialize in their teaching practice looking for a more effective performance in this process.
\end{abstract}

Keywords: Team sports. Training. Motor praxeology

\section{Praxiología motriz: nuevas proposiciones para el entrenamiento de los juegos deportivos colectivos}

\section{RESUMEN}

En proceso de Entrenamiento de los Juegos Deportivos Colectivos (JDCs) vienen sufriendo críticas por el modo como es materializado, pues el entrenador no siempre posee argumentos y métodos de enseñanza que son consistentes con lo que viene siendo defendido en la bibliografía científica. Todavía se percibe un entrenamiento descontextualizado de la lógica de juego, creyendo que el mejoramiento técnico sea capaz de satisfacer todos los elementos que se constituyen los JDCs. Por otro lado, la Praxiología Motriz se presenta como una importante teoría que podrá orientar la práctica pedagógica del entrenador, en la cual sistematiza la lógica interna de esas modalidades. De este modo, se ha realizado una investigación bibliográfica y exploratoria que tuvo como objetivo analizar las implicaciones de los conceptos de la Praxiología Motriz en el proceso de Entrenamiento de los JDCs. A partir de la Praxiología Motriz y sus elementos se ha presentado nuevos presupuestos para el Entrenamiento en el intuito de auxiliar los entrenadores a materializar su práctica pedagógica en la búsqueda hacia el rendimiento más eficaz en este proceso.

Palabras clave: Juegos deportivos colectivos. Entrenamiento. Praxiología motriz 


\section{INTRODUÇÃO}

Os Jogos Esportivos Coletivos (JECs) se constituem por um conjunto de modalidades que englobam disputas entre equipes, no qual contam com a participação de companheiros e de adversários (GRECO, 1998; RIBAS, 2014). Estas práticas possuem alto grau de complexidade devido ao número de interações motrizes estabelecidas entre os participantes (LAGARDERA; LAVEGA, 2003). Dessa forma, existe uma grande variedade de situações que ocorrem no contexto do jogo, apresentando um caráter de aleatoriedade, imprevisibilidade e variabilidade. Conforme Graça (2013), os JECs são modalidades de elevada complexidade e exigência sob os mais diversos pontos de vista, pois apresentam desafios de coordenação motora, de execução das habilidades e de condição física, de ordem cognitiva, tática e estratégica, psicológica, social e moral, representando sempre um desafio aleatório para quem os pratica. Por isso, essas características proporcionam diferentes interpretações para as modalidades, desde as estratégias de jogo no alto rendimento até o ensino em ambientes formativos. Sendo assim, a maneira com que o treinador compreende o jogo e, a partir deste entendimento, a forma com que organiza sua prática pedagógica, serão fatores que irão nortear o desenvolvimento dos atletas.

Os processos de treinamento dos JECs foram, por muito tempo, balizados por concepções cartesianas, atreladas a um pensamento analítico que consistia na fragmentação de fenômenos complexos, para posteriormente se obter o conhecimento do todo (GRACIANO, 1984; MESQUITA, 2006; SANTOS, 1979). Nesta linha de pensamento, muito atrelada ao inatismo e ao empirismo, destacam-se treinamentos descontextualizados da lógica da modalidade e com forte tendência tecnicista, constituindo uma abordagem bastante tradicional e fragmentada da Educação Física no geral e, especialmente, do treinamento esportivo (DAOLIO; VELOZO, 2008; REVERDITO; SCAGLIA, 2009; REVERDITO; SCAGLIA; PAES, 2009).

Uma nova tendência vem a superar este modelo supracitado, confrontando essa perspectiva a partir do um paradigma interacionista. $\mathrm{O}$ todo é compreendido como mais do que a soma das partes, onde os jogadores não são apenas executores de ações motoras, mas sim seres humanos interagindo em um ambiente dinâmico e social (GRECO, 1998; BRAZ, 2013). Destaca-se o denso aporte literário produzido acerca deste panorama (GARGANTA, 1995; GRAÇA, 1995; GRAÇA; MESQUITA, 2002; TAVARES, 2013; BUNKER; THORPE, 1982; MAHLO, 1969; KRÖGER; ROTH, 1999; GRÉHAIGNE, 2001, BAYER, 1994; TEODORESCU, 1977).

Nos dias atuais, ambas as linhas de pensamento são utilizadas cotidianamente. Porém, percebe-se que os modelos de ensino pautados na concepção de entender a técnica dissociável da tática ainda prevalecem no processo de treinamento (RIBAS, 2014). No entanto, para que se possa pensar a metodologia ideal para o treinamento dos JECs, existe, a priori, a necessidade da compreensão da dinâmica do jogo (RIBAS, 2014). A partir disso, a seleção dos conteúdos e dos métodos a serem utilizados deve ser condizente com as demandas existentes nessas práticas, especialmente com a lógica de funcionamento do jogo. De imediato é lançado uma indagação: Qual o conhecimento científico que tem 
sido considerado para desvelar aspectos relativos à dinâmica do jogo? Irão ser defendidos neste texto os instrumentos de análise da Praxiologia Motriz.

Nessa lacuna teórica a Praxiologia Motriz apresenta-se como um conhecimento científico que tem por intuito sistematizar os aspectos referentes à lógica interna das práticas motrizes, proporcionando o entendimento da gramática dos jogos e esportes. Originária da França, em meados de 1960, a Praxiologia Motriz foi criada pelo professor Pierre Parlebas com base na Linguística, Psicologia, Sociologia, além do próprio conhecimento da Educação Física, áreas estas que Parlebas possui formação acadêmica. Assim, a Praxiologia Motriz "apresenta-se como a Ciência da Ação Motriz ${ }^{5}$ e especialmente das condições, modos de funcionamento e resultados de seu desenvolvimento" (PARLEBAS, 2001, p. 354).

Vários estudos praxiológicos vêm apresentando relevantes avanços no processo de desvelar o entendimento de funcionamento dos Jogos Esportivos Coletivos. O primeiro aspecto a ser destacado se refere ao conceito de ação motriz, unidade básica de análise. Este conceito supera a ruptura da técnica e da tática, considerando a manifestação esportiva num contexto sistêmico, onde a mesma só existe a partir das interações de comunicação e contracomunicação existentes no jogo (CESARE; ESPER, 2015; PARLEBAS, 2001). Ao abordar a ação motriz, esta considera as particularidades de cada participante do jogo, de forma ímpar e pessoal a partir do indivíduo atuante no jogo (LAGARDERA; LAVEGA, 2003). O Sistema de Classificação e os modelos Universais irão proporcionar outro ponto de vista distinto a respeito da lógica interna dos JECs, ao contemplarem uma série de elementos para seu entendimento. Ribas (2014) investigou estes elementos no Voleibol, Marques Filho (2016) e Díaz (2015) no Futebol e Rufino (2017) no Rugby, entre outros. Esses estudos apresentam relevantes subsídios ao processo de treinamento dos Jogos Esportivos Coletivos.

Além disso, a Praxiologia Motriz constitui-se em um valioso conhecimento científico para a construção de uma compreensão fidedigna da lógica interna do jogo. Surge então, como interesse desta pesquisa, analisar as implicações dos conceitos da Praxiologia Motriz no processo de treinamento dos Jogos Esportivos Coletivos. A partir disso, busca-se apresentar definições sobre os Jogos Esportivos Coletivos, a Praxiologia Motriz e o processo de Treinamento esportivo. Os conceitos apresentados no decorrer do texto serão pautados nesta tríade, com o intuito de propor novas premissas que poderão orientar substancialmente a prática pedagógica de profissionais da área.

\section{JOGOS ESPORTIVOS COLETIVOS E SUAS DEFINIÇÕES}

Para que se possa construir uma fundamentação acerca de novos pressupostos sobre o processo de treinamento dos JECs, torna-se necessário apresentar conceitos básicos para que o entendimento seja pautado em definições aprofundadas e que tenham

5 Para Lagardera e Lavega (2003), a ação motriz constitui a unidade básica de análise e significado elementar da Praxiologia Motriz, na qual representa as propriedades emergentes do sistema praxiológico, sendo o conceito central das discussões da Praxiologia Motriz. 
reconhecimento dos pesquisadores da área. Dessa forma, segundo Garganta (1998), os JECs caracterizam-se pelo confronto entre duas equipes dispostas em um terreno de jogo que têm como principal objetivo vencer, alternando ações de ataque e defesa. Também, podem ser definidos pela oposição de duas equipes com objetivos idênticos, no caso, marcar pontos e, ao mesmo tempo, evitar pontos da equipe adversária.

Além disso, os JECs são, em sua essência, uma forma de representação social, no qual os jogadores estão dispostos em duas equipes relacionando-se de forma cooperativa e opositiva (LOVATTO; GALATTI, 2007). Conforme Mcgarry et al. (2002), nesta relação ambas as equipes precisam coordenar seus jogadores através de uma estratégia coletiva que considere a oposição da outra equipe num contexto em evolução. De Rose Junior e Silva (2006) os descrevem como modalidades com alto grau de complexidade, pois exigem de seus jogadores interagir com diversos elementos internos a essas práticas. Ao mesmo tempo, Hernández Moreno (1998) advoga que esse grupo de modalidade é definido como uma situação motriz que contempla um caráter de jogo lúdico e institucionalizado.

A partir destas perspectivas, pode-se identificar uma definição pautada nas características pertinentes às relações que o jogo contempla com o espaço e com seus jogadores. As descrições anteriores que conceituam os JECs possibilitam perceber o quão complexo é sua dinâmica de jogo, e assim, consequentemente, seu processo de treinamento. Por isso, é necessário que o treinador utilize de uma teoria que facilite seu entendimento acerca da dinâmica do jogo, para que assim esse processo se torne eficaz na busca pelo resultado desejado.

\section{TREINAMENTO: DEFINIÇÕES E CONCEITOS}

O treinamento esportivo é tema de recorrente discussão no meio acadêmico, principalmente no que tange seu processo metodológico. Barbanti (1994) destaca que o treinamento é um auxílio aplicado ao desenvolvimento das capacidades de rendimento. Casal (2000) discorre que o treinamento pode ser chamado de preparação do esportista, além de ser um processo ontológico que tem como principal objetivo atingir o máximo rendimento. Fabiani (2008), por sua vez, afirma que o treinamento é uma etapa importante e indispensável ao desempenho do atleta, pois consiste em uma organização prática diária, visando alcançar melhor performance no esporte praticado, atingindo-se, com isso, melhores resultados.

Nesse contexto, a capacidade de desempenho que um jogador pode alcançar é o centro do treinamento esportivo, questão alvo de inúmeros questionamentos por parte de estudiosos da área (GRECO, 1998). O mesmo autor salienta que muitas instituições esportivas carecem de estrutura física e de uma filosofia de trabalho coerente com as necessidades e interesses dos praticantes. Por essa razão, muitos erros são cometidos no desenvolvimento das capacidades voltadas ao rendimento.

Adentrando na questão metodológica, pode-se perceber que frequentemente o processo de treinamento é didaticamente separado de duas formas: o treinamento técnico 
e o treinamento tático (GRECO; BENDA, 1998). Nesta perspectiva, o treinamento técnico busca o desenvolvimento das competências necessárias para solucionar as tarefas motoras específicas da modalidade, através do aprimoramento das capacidades coordenativas e técnico-motoras (GRECO; BENDA, 1998). Já o treinamento tático, conforme Greco (1998), busca desenvolver a capacidade do jogador em relacionar suas alternativas e planos de ações e de seus adversários, para que assim consiga com êxito a eficiência em sua ação nas mais variadas situações de jogo.

Porém, ao se pensar na dinâmica dos JECs, a técnica e a tática surgem como elementos indissociáveis, ao passo que um complementa o outro. Sendo assim, "a verdadeira dimensão da técnica repousa na sua utilidade para servir a inteligência e a capacidade de decisão tática dos jogadores e das equipes" (GARGANTA; PINTO, 1994, p. 101). Dessa forma, a qualificada performance esportiva não se restringe em executar com eficiência um conjunto de técnicas, mas, sobretudo, contribuir de forma cooperativa e inteligente para o sucesso do empreendimento coletivo (DAOLIO, 2002).

A partir desse pressuposto, emerge o conceito de treinamento técnico-tático, que apesar de difundido, frequentemente não é compreendido em sua totalidade (SANTOS, 1979; GRACIANO, 1984; GRECO, 1998; RIBAS, 2014). Com os conceitos acima descritos torna-se possível perceber que o treinamento técnico visa o desenvolvimento das habilidades motoras (técnicas) para resolver as situações-problema que o jogo impõe. Para que se consiga perceber qual é o problema e como solucioná-lo, o conhecimento tático desenvolvido pelo treinamento torna-se indispensável. Dessa forma, consequentemente, entende-se que o treinamento técnico deverá ser atrelado ao treinamento tático.

Nesse contexto, no qual os jogadores caracterizam-se pelas suas peculiaridades técnicas, a observação, quando voltada ao jogo, deve interligar fatores técnicos a esfera tática (GARGANTA, 1997; MESQUITA, 2013). Portanto, na busca de atingir o objetivo do treinamento nos JECs, torna-se necessário que se apresente possibilidades para que os jogadores desenvolvam as capacidades destacadas anteriormente. Com isso, os treinadores têm o desafio de selecionar estratégias para que os jogadores aprendam a tomar decisões rapidamente e de maneira eficaz, para então resolver as situações-problema impostas pelo esporte (FILGUEIRA; GRECO, 2008).

\section{PRAXIOLOGIA MOTRIZ: NOVOS CONCEITOS PARA OS JOGOS ESPORTIVOS COLETIVOS}

A Praxiologia Motriz surge como tema de interesse nesta pesquisa por dedicar-se ao estudo da lógica interna de jogos e esportes a partir das regras ou normas de seu funcionamento (LAGARDERA; LAVEGA, 2003). A lógica interna, por sua vez, é caracterizada por Parlebas (2001, p. 302) como um "sistema de características relevantes de uma situação motriz e as consequências que isso implica para a realização da ação motriz correspondente". Com isso, pode-se entender que a Praxiologia Motriz possibilita o estudo da estrutura interna dos jogos e esportes através de suas características relevantes, as quais implicam 
diretamente na realização das ações motrizes específicas de cada modalidade. Desse modo, estes novos conceitos referenciados por essa teoria permitem o entendimento da dinâmica das mais variadas práticas motrizes, incluindo os Jogos Esportivos Coletivos (RIBAS, 2014).

A lógica interna abrange conceitos relevantes e essenciais para o entendimento dos jogos e esportes. Entretanto, tem-se a necessidade de detalhar a estruturação básica para se compreender este universo de manifestações culturais. Os Universais, caracterizados como modelos operacionais que representam as estruturas básicas de funcionamento das práticas motrizes, surgem para preencher essa lacuna (PARLEBAS, 2001). Cada Jogo Esportivo Coletivo apresenta um sistema de interação, uma unidade própria vasta e complexa, que o distingue dos demais. A particularidade de cada uma dessas modalidades detém uma poderosa organização interna, na qual uma série de elementos de sua lógica interna baliza-se como princípio unificador de produções aparentemente heterogênicas.

Neste sentido, essa modelação proposta pelos Universais não significa que as condutas dos jogadores estão estreitamente predeterminadas, mas sim que o sistema sobre o qual elas se realizam está objetivamente pré-estabelecido (PARLEBAS, 2003). Segundo o mesmo autor, o jogador segue tendo um considerável poder de decisão motriz e de autonomia, porém, indiscutivelmente, o canaliza em modelos de execução e em estilos relacionais impostos previamente (PARLEBAS, 2003). Os Universais são compostos por sete modelos operativos, criados a partir de critérios relativos à interação entre os participantes, formas de pontuação, funções exercidas no jogo e às formas de comunicação entre os jogadores. São eles: Rede de Comunicação Motriz, Rede de Interação de Marca, Sistema de Pontuação, Papel Sociomotor, Subpapel Sociomotor, Gestema e Praxema (PARLEBAS, 2001). Desse modo, esses modelos irão organizar e fornecer subsídios teóricos para estabelecer novas proposições para o processo de treinamento dos Jogos Esportivos Coletivos.

\section{METODOLOGIA}

Esse estudo consiste em uma pesquisa de cunho exploratório, pois levanta informações sobre um objeto específico, delimitando o campo de pesquisa e mapeando as manifestações desse objeto (SEVERINO, 2007). Para tal se utilizou da revisão bibliográfica, através de consultas em artigos científicos e livros especializados acerca do tema. Segundo Severino (2007), a pesquisa bibliográfica é aquela realizada a partir de registros disponíveis decorrentes de pesquisas anteriores e utiliza-se de dados ou de categorias teóricas já trabaIhadas por outros pesquisadores. Essa categoria põe o pesquisador em contato direto com todo o material que foi produzido sobre determinado assunto (LAKATOS; MARCONI, 2003).

Devido ao momento inicial das produções que relacionam a Praxiologia Motriz e o Treinamento Esportivo, optou-se por utilizar técnicas de revisão de literatura narrativa, que proporcionam um contexto amplo e subjetivo de coleta de dados e seleção de material a partir das demandas do autor e das características da pesquisa (BERNARDO; NOBRE; JATENE, 2004). Para orientar a busca do referencial teórico utilizou-se os critérios propostos por Salvador (1986): parâmetro temático, parâmetro linguístico, principais fontes 
e parâmetro cronológico. Ao lançar mão desses conceitos na organização da bibliografia escolhida, foram consideradas como parâmetro temático obras que advogam sobre os Jogos Esportivos Coletivos, o processo de treinamento e seus principais conceitos, além da Praxiologia Motriz e seus elementos. No que diz respeito ao parâmetro linguístico, optou-se por obras em português, devido à facilitação na interpretação dos dados, bem como obras em espanhol por serem referências clássicas relacionadas à Teoria da Ação Motriz. Para que fosse possível a utilização de todas as obras pertinentes acerca do tema e para não perder informações relevantes, optou-se por não fazer um recorte temporal do referencial teórico, justificando a utilização de todas as obras e autores empregados na investigação.

Além disso, essa pesquisa apresentou novas proposições no que se refere ao uso da Praxiologia Motriz no processo de treinamento dos Jogos Esportivos Coletivos. Nesse sentido, segundo Salvador (1986), o objetivo de propor algo é oferecer argumentos que demonstrem a importância daquilo que está sendo defendido. Para isso, à medida que se utiliza de estudos que já apresentam conceitos difundidos, se está auxiliando na comprovação destas proposições (GIL, 2008). Assim, na referida pesquisa foram apresentados novos conceitos a ser utilizados no processo de treinamento, na busca pelo entendimento da dinâmica dessas modalidades esportivas.

Outros estudos que estão relacionados com a temática da pesquisa foram utilizados para estabelecer a relação entre a Praxiologia Motriz e o Treinamento dos Jogos Esportivos Coletivos. Para isso, fez-se uso de determinadas obras que apresentam conducentes considerações para o referencial teórico da pesquisa, como Greco (1998), Graça (2013), Parlebas (2001), Garganta (1998), Barbanti (1994), entre outros. Dessa forma, inicialmente, levantou-se conceitos básicos dos autores que vem discorrendo sobre os temas. Após o levantamento das bases bibliográficas e da interpretação dos conceitos centrais destacados pela literatura, relacionou-se as referidas temáticas e estabeleceu-se novos pressupostos, com o intuito de analisar a lógica de funcionamento dos Jogos Esportivos Coletivos. Para isso, utilizou-se como aporte praxiológico o Sistema de Classificação CAl e os Universais, ambos elementos conceituais da Praxiologia Motriz.

\section{RESULTADOS E DISCUSSÃO}

Ao se pensar uma teoria científica que contemple a demanda de cada modalidade esportiva, a compreensão aprofundada de sua lógica interna torna-se crucial. Neste sentido, a Praxiologia Motriz emerge como teoria fundamental para esse processo. Um de seus conhecimentos a ser destacado é o Sistema de Classificação CAI, elaborado a partir do conceito de lógica interna, constituindo-se como uma ferramenta criteriosa e científica. O CAI tem por finalidade classificar as mais diferentes práticas motrizes e caracterizá-las conforme a presença ou a ausência de companheiros e/ou adversários e a relação com o entorno físico.

De acordo com essa classificação, os JECs configuram-se como práticas sociomotrizes de cooperação e oposição, pelo fato dos jogadores manterem interações de comunica- 
ção entre companheiros de equipe e de contracomunicação entre adversários. Para Ribas (2014), a interação motriz está relacionada com a essência de qualquer prática motriz e, portanto, nessas modalidades, quanto melhor for a comunicação entre os jogadores, maior a possibilidade de êxito na tarefa para opor-se aos adversários, ampliando as alternativas táticas e, consequentemente, o processo de tomada de decisão demandado pelo jogo.

Esse entendimento, a priori, contraria métodos que compreendem a técnica de forma desconexa do contexto tático, no qual prioriza o treinamento dos fundamentos técnicos fragmentados do ambiente de jogo. Ao se treinar condução de bola no futebol entre cones ou arremesso no handebol em frente a uma parede, por exemplo, não se está considerando os elementos de interação que essas ações motrizes terão no contexto do jogo. Todavia, há indícios suficientes para que o conceito de técnica supere a simples reprodução e repetição de movimentos (RIBAS, 2014). Segundo Mesquita (2013), o jogo é constituído por componentes técnicos e táticos, sendo que a técnica está embutida na constituição da tática. Corroborando com essa ideia, Ribas (2014) salienta que sacar no voleibol não se constitui somente em uma ação dita técnica, mas está relacionada com um aprofundado conhecimento tático.

O conceito de ação motriz contrapõe esse entendimento fragmentado das ações de jogo ao englobar os conceitos de ação técnica e tática como indissociáveis entre si e em relação ao contexto do jogo (RIBAS, 2014). Portanto, no que diz respeito aos JECs, ao se propor o treinamento pautado no desenvolvimento das ações motrizes, este deverá evidenciar situações com interação motriz entre companheiros e adversários. A possibilidade de propor situações de jogo, em suas diferentes estruturas, permitirá ao participante qualificar sua aprendizagem, pois seus sistemas de memória (reconhecimento e recordação) estarão diretamente ligados ao sistema de recepção, transmissão e elaboração de informações já trabalhadas nas formas de jogo (GRECO, 1998).

Desta forma, ao atuar no jogo, cada participante é portador de mensagens, por isso estabelece uma relação de comunicação entre companheiros e de contracomunicação entre adversários, visto que esse processo ocorre através de mensagens transmitidas por todos os jogadores. Essas mensagens são passíveis de decodificação por parte dos demais participantes e, portanto, devem ser transmitidas de forma clara aos companheiros, e, simultaneamente, devem conter um caráter de dificuldade para que não sejam decodificadas por seus adversários (RIBAS, 2014). Para Lavega (2008), esses processos de codificação e decodificação exigem que o comportamento dos jogadores seja predominantemente relativo à tomada de decisão, adaptado, portanto, às características de seus companheiros e adversários.

A partir da comunicação e da contracomunicação pertencentes à lógica interna dos JECs, surgem novos procedimentos que organizam a estrutura de percepção da tomada de decisão para atingir a eficácia na realização da ação motriz necessária e assim solucionar os problemas impostos pelas situações de jogo. Neste sentido, Lagardera e Lavega (2004) destacam os processos ativados e os processos resultantes do sistema praxiológico. Esses preceitos derivam das características referentes às interações motrizes de cooperação e oposição que compõem os JECs. Para melhor esclarecimento, apresenta-se a figura a seguir. 


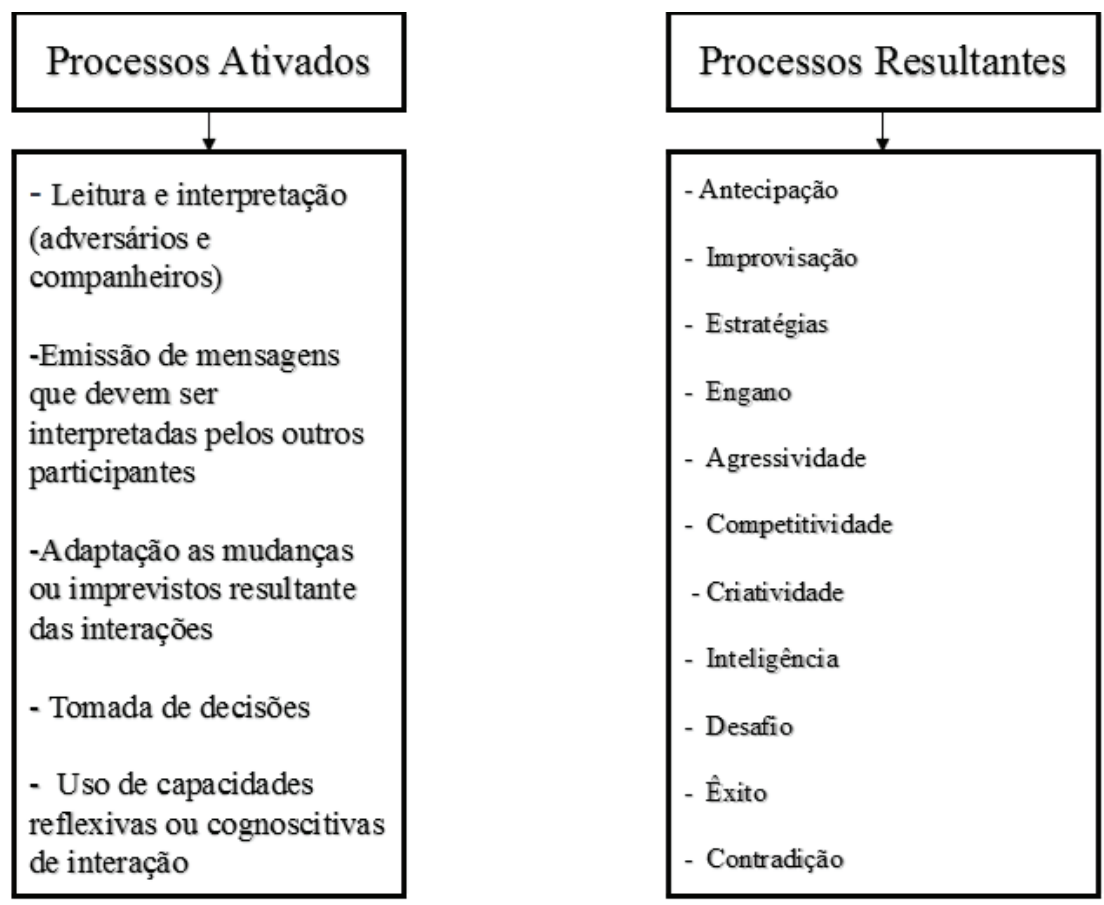

Figura 1 - Processos Ativados e Processos Resultantes dos Jogos Esportivos Coletivos provenientes de sua lógica interna. Fonte: Adaptada de Lagardera e Lavega (2004).

Com relação aos modelos operativos propostos pelos Universais, cujo intuito é organizar de maneira estrutural as práticas motrizes, pode-se ampliar o entendimento referente à cada modalidade esportiva específica. Dentre estes modelos, a Rede de Comunicação Motriz permite estudar as diferentes formas como os jogadores interagem entre si, evidenciando as interações motrizes que sucedem em cada prática motriz. Como já descrito anteriormente, os JECs são práticas sociomotrizes de cooperação e oposição, pois os jogadores se relacionam com companheiros e, simultaneamente, com adversários.

Portanto, é de suma importância que se considere as duas formas de interação presentes nos JECs no momento do treinamento, caso contrário os praticantes poderão ter maior dificuldade de leitura dos demais jogadores, sejam eles companheiros ou adversários, e, consequentemente na tomada de decisão. Entretanto, os treinadores poderão se utilizar de estruturas de atividades que não contemplem companheiros e/ou adversários, dando maior ênfase para um aspecto ou outro (técnica e tática), de acordo com a necessidade avaliada. Todavia esse critério de comunicação e contracomunicação deve ser ferramenta norteadora do treinamento, balizando a maior parte desse processo, pois em uma perspectiva macro a organização do treinamento deve contemplar as demandas da lógica do jogo. 
Com isso, também se tem um avanço em relação ao princípio didático que vem apontando para uma ordem cronológica no processo de treinamento, fazendo com que o ensino técnico seja pré-requisito para o aprendizado tático. Assim, para Lagardera e Lavega (2003), cada prática motriz possui uma organização própria e comporta suas respectivas estruturas, evidenciando as características relevantes a serem incorporadas no processo de treinamento. Desse modo, tanto o processo de comunicação quanto de contracomunicação devem ser elementos centrais a ser desenvolvidos durante o treinamento dos JECs (HERNÁNDEZ MORENO, 2000).

A Rede de Interação de Marca tem por objetivo ressaltar o que deve ser feito para obter a vitória no jogo, ou seja, indica a interação motriz necessária para vencer determinada prática motriz. Segundo Lagardera e Lavega (2003) a Rede de Interação de Marca pode ser de três tipos: antagônica (êxito a partir da oposição), cooperativa (êxito com base na cooperação) ou mista (pode resultar da cooperação e/ou da oposição). Assim sendo, os JECs assumem a característica da rede antagônica, pois só é possível pontuar nessas práticas motrizes através da interação de contracomunicação, ou seja, se opondo aos adversários.

No entanto, é de suma importância que fique elucidado que ambas as interações são primordiais para a dinâmica e funcionalidade do jogo, pois não existe um cooperar por cooperar e tão pouco a oposição por si só, mas sim um cooperar com o intuito de opor-se ao adversário, ao mesmo tempo que a oposição vem da relação de cooperação (RIBAS, 2014). Contudo, é necessário que no processo de treinamento seja explicitado que a cooperação, assim como a oposição, são elementos vitais para a funcionalidade do jogo, pois se uma delas não for bem estabelecida, a outra não será realizada de maneira eficaz, uma vez que ambas estão articuladas.

Outro modelo operativo pertencente aos Universais é o Sistema de Pontuação. Segundo Parlebas (2001), este se caracteriza pelos pontos marcados pela equipe, estabelecido pelo regramento que determina o jogo. Na iniciação ao treinamento, a compreensão de como se estabelece o sistema de pontuação da modalidade torna-se extremamente necessária para que haja, desde o início do processo, um maior entendimento de como a equipe deve se organizar taticamente para conquistar os pontos durante a partida. Isto é, como os companheiros de equipe devem se organizar de maneira estratégica, cooperando adequadamente para superar seus adversários e assim marcar pontos. O entendimento do Sistema de Pontuação faz-se necessário principalmente em práticas que não são características de nosso meio cultural, sendo, portanto, mais complexas para assimilação, como por exemplo o futebol americano e o rugby.

O Sistema de pontuação também exerce influência circunstancial no aspecto tático do jogo. Uma equipe que se encontra em desvantagem no placar, terá de dar ênfase às questões ofensivas, mesmo que isso acarrete maior vulnerabilidade defensiva, por exemplo. O processo de treinamento, portanto, também deve contemplar este tipo de situação, simulando momentos de vantagem ou adversidade com relação ao placar e/ou tempo de jogo (MADEIRA; NAVARRO, 2012). Aspectos emocionais, atitudinais e de organização tática serão trabalhados de forma a se aproximarem de situações reais encontradas em uma partida de determinada modalidade esportiva coletiva. 
No Voleibol, por exemplo, modalidade na qual as regras do jogo indicam a necessidade de pontuação limite, o treinador deverá ocupar-se em olhar para as distâncias do escore do jogo. Por exemplo: jogo equilibrado, jogo onde a minha equipe apresenta uma boa vantagem e jogo onde a equipe adversária apresenta uma boa vantagem. Diferentes possibilidades táticas e objetivos na partida poderão surgir a partir desse sistema de pontuação. Em modalidades cujo tempo limite orienta o final do confronto (futebol, basquetebol e handebol, por exemplo), o treinador poderá se utilizar de um trabalho de inferioridade no placar se o mesmo for suficiente para atingir uma vitória em um confronto "ida-volta", pois muitas vezes o regulamento da competição permite. Da mesma forma, que a organização tática ocorre de maneira diferente, pois para se atingir o êxito necessita-se fazer gols e não tomar. Diferentes desdobramentos poderão surgir para cada forma de finalizar uma partida.

No que diz respeito às funções exercidas no jogo, o Papel Sociomotor refere-se à classe de comportamentos motores associada a um regulamento preciso em um jogo esportivo, no qual está relacionado a um estatuto que codifica a prática motriz (PARLEBAS, 2001). Além disso, o Papel Sociomotor está diretamente associado à maneira como cada participante pode atuar no jogo, e por essa razão altera-se frequentemente. A definição dos Papeis pode ser realizada seguindo diferentes critérios. Nos JECs, quando se considera o material, o critério utilizado é a posse de bola, no caso: jogador com bola, jogador sem bola da equipe que tem a posse e jogador da equipe que não tem a posse (HERNÁNDEZ MORENO; RODRIGUES RIBAS, 2004). Se o critério for baseado no espaço de jogo, no caso do futebol e do handebol, os Papeis podem ser jogador de linha e goleiro. Já no voleibol: sacador, defensor, atacante e líbero. Segundo Hernández Moreno e Rodrigues Ribas (2004), ainda existe um terceiro critério referente às zonas de campo/quadra que ao exemplo do futebol são divididos em goleiro, defensores, meio-campistas e atacantes. Portanto, será estritamente atrelado ao que a regra permite a cada jogador e a cada modalidade esportiva conforme sua lógica interna.

O Subpapel Sociomotor refere-se às unidades comportamentais que um sujeito pode realizar em cada Papel, permitindo ver toda gama de possibilidades de agir em cada um dos referidos Papeis (PARLEBAS, 2001). Os Subpapeis são atinentes a cada ação motriz possível para um determinado Papel e representam a sequência motriz de um jogador, considerada como uma unidade básica de comportamento estratégico (LAGARDERA; LAVEGA, 2003). Neste sentido, este Universal desvela por meio de quais ações motrizes o atleta poderá atuar no jogo. Segundo Parlebas (2001), os estudos das características dos Subpapeis de cada jogo esportivo podem evidenciar novos conhecimentos sobre os mesmos. Essas propriedades ajudam a explicar alguns recursos importantes sobre a lógica interna do jogo e, consequentemente, deverão estar contemplados no treinamento esportivo.

Desse modo, compreender profundamente os Papeis e os Subpapeis de cada modalidade que se pretende treinar, torna-se crucial. É necessário conhecer como cada participante pode atuar no jogo para proporcionar estruturas de atividades que contemplem esses elementos, bem como trabalhar com a dinâmica de troca constante de Papeis e, por consequência, de Subpapeis. A assimilação dos modelos dos Universais pode, por exemplo, ajudar a responder as seguintes perguntas: É importante jogar sem a bola? Mas 
como o jogador pode atuar sem a bola? Que papeis ele pode exercer? Como se dará essa participação no jogo? Estes questionamentos se caracterizam por uma série de lacunas que, a partir da Praxiologia Motriz, são preenchidas para o desenvolvimento do processo de treinamento.

Em relação às formas de comunicação entre os jogadores, o Gestema estará fortemente presente em etapas iniciais do treinamento dos JECs. Este se refere às posturas e gestos convencionais que transmitem uma pretensão ou indicação aos demais jogadores (PARLEBAS, 2001). O Gestema permite a transmissão de mensagens de forma clara, por meio de gestos e sinais visuais, facilitando a compreensão por parte dos companheiros (RIBAS, 2014). No entanto, são também facilmente interpretadas pelos adversários, uma vez que sua leitura e interpretação permitem a decodificação dessas mensagens. Com isso, quanto mais se eleva o nível de performance e treinamento, as transmissões de mensagem passam a ocorrer de forma mais sutil.

Dessa forma, o Gestema, gradativamente, dá lugar ao Praxema. Assim, a contracomunicação torna-se mais elaborada, ao passo que ganha relevância na dinâmica do jogo. Conforme Lagardera e Lavega (2003), os Praxemas são comportamentos de "pré-ação", com uma mensagem tática ou relacional. É o comportamento motriz de um jogador interpretado como um signo, servindo como indício da ação motriz que o jogador irá realizar (PARLEBAS, 2001). Da mesma forma, o Praxema é passível de leitura, o que permitirá a antecipação por parte de todos os jogadores, sendo por esse motivo que ele deve ser claro e preciso para os seus companheiros e o mais obscuro possível e incerto para seus adversários.

No processo de treinando dos Jogos Esportivos Coletivos é importante que o treinador proporcione aos seus atletas estruturas de atividades que comtemplem esses elementos. No Futebol, por exemplo, torna-se mais relevante que o jogador conduza a bola procurando realizar o drible em outro jogador do que em cones, pois os cones não fornecerão nenhuma oposição, e consequentemente o jogador não precisará realizar a leitura. Da mesma forma, no Voleibol, destaca-se que no momento de realizar o treinamento do levantador coloquem-se bloqueadores induzindo o local para onde se deslocarão, fazendo com que o levantador procure antecipar sua ação em virtude da leitura realizada. Nessa perspectiva, os jogadores devem ter a capacidade de compreender o significado tático dos movimentos dos outros jogadores (companheiros e adversários), ou seja, aprender a decifrar os praxemas e gestemas do jogo. O processo treinamento dessas capacidades é longo e complexo, exigindo uma série de ações didáticas, como modificações do jogo para proporcionar o desenvolvimento dessas competências (JIMÉNEZ; GOROSTIAGA, 2015).

Possuir um conhecimento sobre os processos e as formas de comunicação entre os jogadores é de grande relevância, pois a estrutura de leitura de jogo, pautada no entendimento das ações dos companheiros e adversários, fica mais evidente, e dessa forma possibilita a melhor tomada de decisão para resolver as situações defrontadas. O jogo é um sistema complexo que exige de seus jogadores competência para reconhecer sua lógica de funcionamento (saber tático-estratégico) (SCAGLIA; REVERDITO; GALATTI, 2013).

Assim, torna-se necessário que o jogador tenha boa capacidade de ler o jogo e pautar suas ações motrizes a partir das interpretações realizadas através do processo de leitura 
de jogo. A interpretação só se tornará possível se os processos comunicativos estiverem presentes no treinamento, pois se o treinador o balizar apenas por estruturas de atividades lineares, esses desdobramentos não serão comtemplados. Logo, é imprescindível ter o conhecimento acerca da lógica de funcionamento dessas modalidades, uma vez que essa pode ser contemplada através de situações de jogo, pois é nelas que a imprevisibilidade aparece (MOGADOURO, 2012). Por isso, se o treinamento não abordar essas características, ele não estará abrangendo e contemplando os elementos essenciais dos Jogos Esportivos Coletivos, o que pode vir a comprometer o objetivo traçado no planejamento do treino.

\section{CONCLUSÕES}

Tendo em vista que o objetivo do estudo foi analisar as implicações dos conceitos da Praxiologia Motriz no processo de treinamento dos Jogos Esportivos Coletivos, os conhecimentos propostos para este processo visaram superar alguns modelos e princípios pautados principalmente no senso comum, sem embasamento categorizado cientificamente. Assim, em relação à dinâmica das modalidades coletivas, acredita-se ser insuficiente que os treinadores abordem e desenvolvam apenas a reprodução de gestos técnicos descontextualizados do jogo. Como destacado anteriormente, os JECs são modalidades caracterizadas pela sua aleatoriedade de ações técnico-táticas, sendo necessária, portanto, a compreensão dos elementos relevantes que compõem essas práticas motrizes. Para que haja eficiência no processo de treinamento deve-se considerar os elementos da lógica interna dos JECs, a fim de que os jogadores executem as ações motrizes necessárias e de maneira eficiente para a solução das tarefas-problemas.

A Praxiologia Motriz traz a categorização da lógica interna do jogo, destacando as interações motrizes que estruturam os JECs e, para melhor modelização, dispõe do Sistema de Classificação CAI e dos Universais que permitem conhecer o funcionamento das modalidades coletivas. Assim, a Rede de Comunicação Motriz salienta as interações motrizes que compõe os JECs e a importância destas relações para o processo comunicativo, de modo a transmitir mensagens claras a seus companheiros e obscuras aos oponentes de equipe, mediante gestos e signos corporais, através do Gestema e do Praxema, respectivamente. O Papel e o Subpapel Sociomotor propiciam que o jogador compreenda suas funções e suas possibilidades de atuação oriundas do Papel estabelecido pelo participante conforme o sistema de regras, para assim atingir o desempenho individual e coletivo.

O Sistema de Pontuação destaca como se estabelece a pontuação nos JECs e a importância desse entendimento desde perspectivas de organização tática até estratégica. Por fim, a Rede de Interação de Marca diz respeito a quais interações motrizes são necessárias para a obtenção da vitória nos diferentes JECs e a importância desses conhecimentos para o desempenho do atleta no contexto do jogo. No que tange aos elementos praxiológicos aliados ao treinamento, percebeu-se que é essencial que os treinadores se apropriem desses conceitos e durante o processo de treinamento estimulem seus atletas a compreenderem o jogo, pois a partir disso a eficácia no desempenho será maior e os objetivos traçados serão contemplados. 
Vale salientar que a Praxiologia Motriz não é um método de ensino e tão pouco uma concepção pedagógica, mas sim uma teoria que apresenta conceitos que merecem e devem ser mais bem aprofundados. Por isso, é importante a utilização de métodos não lineares que possibilitem a materialização desses conceitos sustentados pela Teoria da Ação Motriz. Atualmente, a discussão acerca dos métodos vem se expandindo, no qual tem-se apresentado diversos modelos baseados nessas características de ensino. Dessa forma, constatou-se, a partir dos resultados da pesquisa, que o processo de treinamento deve ser pautado nessas arestas do conhecimento, pois apresentam significativos e vastos avanços para a prática pedagógica do treinador, trazendo à tona novos conhecimentos para o ensino dos Jogos Esportivos Coletivos.

À medida que se apresentou algumas contextualizações acerca da Praxiologia Motriz, torna-se importante investir em estudos que avaliem os conceitos discorridos ao longo dessa pesquisa. É importante que os treinadores proponham intervenções sustentadas pelos conhecimentos da Praxiologia Motriz, articulando essas propostas teóricas as suas metodologias de treinamento. Nesse momento as discussões abordadas até aqui fornecem um valioso subsídio teórico para balizar o processo de treinamento, bem como para o conhecimento do treinador. Assim, posteriormente percebe-se a necessidade essas aplicações em no processo de treinamento dos Jogos Esportivos Coletivos.

\section{REFERÊNCIAS}

BARBANTI, V. J. Dicionário de Educação Física e do Esporte. São Paulo: Manole, 1994. BAYER, C. O ensino dos desportos coletivos. Lisboa: Dina livros, 1994.

BERNARDO, W. M.; NOBRE, M. R. C.; BISCEGLI JATENE, F. A Prática Clínica Baseada em Evidências. Parte II - Buscando as Evidências em Fontes de Informação. Revista Associação Médica Brasileira, São Paulo, vol. 50, n. 1, 2004.

BRAZ, T. V. Análise de Jogo no Futebol: considerações sobre o componente técnico-tático, planos de investigação, estudos da temática e particularidades do controle das ações competitivas. Revista Brasileira de Futsal e Futebol, São Paulo, v. 5, n. 15, p. 28-43, 2013.

BUNKER, D.; THORPE, R. A Model for the Teaching of Games in Secondary Schools. Bulletin of Physical Education, v. 18, n. 1, p. 5-8, 1982.

CASAL, H. M. V. Treinamento Desportivo e Psicologia do Esporte. Revista Brasileira de Ciência e Movimento, Brasília, v. 8, n. 4, p. 37-44, 2000.

CESARE, P. E. D.; ESPER, N. P. Praxiología y Baloncesto: Hacia una Enseñanza Comprensiva y Significativa del Mini-Baloncesto. Acción Motriz, n. 4, p. 35-44, 2015.

DAOLIO, J. Jogos Esportivos Coletivos: dos princípios operacionais aos gestos técnicosmodelo pendular a partir das ideias de Claude Bayer. Revista Brasileira de Ciência e Movimento, Porto Alegre, v. 10, n. 4, p. 99-103, 2002.

DAOLIO, J.; VELOZO, E. L. A Técnica Esportiva Como Construção Cultural: Implicações para a Pedagogia do Esporte. Pensar A Prática, v. 11, n. 1, p. 9-16, 2008. 
julho/2018

DE ROSE JUNIOR; SILVA, T. A. F. As Modalidades Esportivas Coletivas (MEC): história e caracterização. In: DE ROSE JUNIOR (Org.). Modalidades Esportivas Coletivas. Rio de Janeiro: Guanabara Koogan, 2006, p. 1-14.

DÍAZ, R. D. Análisis Praxiológia de la Dinámica de Juego em Fútbol: Lógica Externa y Lógica Interna. 2015. 437 f. Tese (Doutorado em Praxiologia Motriz, Educação Física e Treinamento Desportivo) - Departamento de Educación Física, Universidad de Las Palmas de Gran Canaria, Las Palmas de Gran Canaria, 2015.

FABIANI, M. T. Psicologia do Esporte: a ansiedade e o estresse pré-competitivo. In: CONGRESSO NACIONAL DE EDUCAÇÃO: EDUCERE, 8., Curitiba, 2008. Anais eletrônicos... Curitiba: Pontifícia Universidade Católica do Paraná, 2008. p. 1233712345. Disponível em: <http://www.pucpr.br/eventos/educere/educere2008/anais/ pdf/182_454.pdf>. Acesso em: 01 set. 2016.

FILGUEIRA, F. M.; GRECO, P. J. Futebol: um estudo sobre a capacidade tática no processo de ensino-aprendizagem-treinamento. Revista Brasileira de Futebol, Viçosa, v. 1, n. 2, p. 53-65, 2008.

GARGANTA, J. O Ensino dos Jogos Desportivos Coletivos: perspectivas e tendências. Movimento, Porto Alegre, v. 1, n. 8, p. 19-26, 1998.

GARGANTA, J. Para una Teoría de los Juegos Deportivos Colectivos. In: GRAÇA, A.; OLIVEIRA, J. (Orgs.). La Enseñanza de los Juegos Deportivos. Barcelona: Paidotribo, 1997, p. 9-24.

GARGANTA, J.; PINTO, J. O Ensino do Futebol. In: GRAÇA, A.; OLIVEIRA, J. (Eds.). O Ensino dos Jogos Desportivos. Editora Porto: Universidade do Porto, 1994, p. 97-137. GIL, A. C. Métodos e Técnicas de Pesquisa Social. 6. ed. São Paulo: Atlas, 2008.

GRAÇA, A. Os contextos sociais do Ensino e Aprendizagem dos Jogos Desportivos Coletivos. In: NASCIMENTO, J. V.; RAMOS, V.; TAVARES, F. (Orgs.). Jogos Desportivos: formação e investigação. Florianópolis: UDESC, 2013, p. 79-102.

GRAÇA, A; MESQUITA, I. R. A Investigação Sobre o Ensino Dos Jogos Desportivos: Ensinar a Aprender as Habilidades Básicas do Jogo. Revista Portuguesa de Ciências do Desporto, Porto, v. 2, n. 2, p. 67-79, 2002.

GRACIANO, V. A Arte e a Técnica do Futebol. São Paulo: Roswhita Kempf, 1984.

GRECO, P. J. Iniciação Esportiva Universal: metodologia da iniciação esportiva na escola e no clube. Belo Horizonte: UFMG, 1998.

GRECO, P. J.; BENDA, R. N. Iniciação Esportiva Universal: da aprendizagem motora ao treinamento técnico. Belo Horizonte: UFMG, 1998.

GRÉHAIGNE, J. F. La Organización del Juego en el Fútbol. Barcelona: INDE, 2001.

HERNÁNDEZ MORENO, J. Fundamentos del Deporte: análisis de las estructuras del juego deportivo. 2. ed. Barcelona: INDE Publicaciones, 1998.

HERNÁNDEZ MORENO, J. La Iniciación a los Deportes desde su Estructura y Dinámica: aplicación a la educación física escolar y al entrenamiento deportivo. Barcelona: INDE, 2000.

HERNÁNDEZ MORENO, J.; RODRIGUEZ RIBAS, J. P. La Praxiologia Motriz: fundamentos y aplicaciones. Barcelona: INDE Publicaciones, 2004. 
JIMÉNEZ, D. M.; GOROSTIAGA, R. M. S. Data Quality Control of an Observational Tool to Analyze Football Semiotricity. Cuadernos de Psicología del Deporte, v. 15, n. 1, p. 223-232, 2015.

KRÖGER, C.; ROTH, K. Ballschule: Ein ABC für Spielanfänger. Schorndorf: Hofmann, 1999. LAGARDERA, F.; LAVEGA, P. Introducción a la Praxiología Motriz. Barcelona: Paidotribo, 2003.

LAGARDERA, F.; LAVEGA, P. La Ciencia de la Acción Motriz. Lleida: Universitat de Lleida, 2004.

LAKATOS, E. M.; MARCONI, M. A. Fundamentos de Metodologia Científica. 5. ed. São Paulo: Atlas, 2003.

LAVEGA, P. Classificação dos Jogos, Esportes e as Práticas Motrizes. In: RIBAS, J. F. M. (Org.). Jogos e Esportes: fundamentos e reflexões da Praxiologia Motriz. Santa Maria: UFSM, 2008, p. 81-104.

LOVATTO, D. L.; GALATTI, L. R. Pedagogia do Esporte e Jogos Esportivos Coletivos: das teorias gerais para a iniciação esportiva em basquetebol. Revista Movimento e Percepção, v. 8, n. 11, p. 268-277, 2007.

MADEIRA, D. R. I.; NAVARRO, A C. A escolha da Metodologia de Treinamento de Futsal como Ferramenta Fundamental para a Formação de Atletas e Estruturação do Jogo. Revista Brasileira de Futsal e Futebol, Edição Especial: Pedagogia do Esporte, São Paulo, v. 4, n. 14, p. 239-244, 2012.

MAHLO, F. O Acto Táctico no Jogo. Lisboa: Compedium, 1969.

MARQUES FILHO, C. V. A estruturação do futebol e seus elementos pedagógicos: uma visão a partir da Praxiologia Motriz. 2017. 78 f. Dissertação (Mestrado em Educação Física) - Universidade Federal de Santa Maria, 2017.

MCGARRY, T.; ANDERSON, D.; WALLACE, S.; HUGHES, M.; FRANKS, I. Sport Competition as a Dynamical Self-Organizing System. Journal of Sport Sciences, v. 20, p. 771-781, 2002.

MESQUITA, I. Ensinar bem para aprender melhor o Jogo de Voleibol. In: TANI, G.; BENTO, J.; PETERSEN, R. (Orgs.). Pedagogia do Desporto. Rio de Janeiro: Guanabara Koogan, 2006, p. 327-343.

MESQUITA, I. Perspectiva Construtivista da Aprendizagem no Ensino do Jogo. In: NASCIMENTO, J. V.; RAMOS, V.; TAVARES, F. (Orgs.). Jogos Desportivos: formação e investigação. Florianópolis: UDESC, 2013, p. 103-133.

MOGADOURO, A. Formação dos Jogos Desportivos Coletivos. 2012. 57 f. Dissertação (Mestrado em Educação Física) - Faculdade de Desporto da Universidade do Porto, 2012.

PARLEBAS, P. Elementos de Sociología del Deporte. Málaga: Instituto Andaluz del Deporte, 2003.

PARLEBAS, P. Jogos, Deportes y Sociedade: léxico de praxiología motriz. Barcelona: Paidotribo, 2001.

REVERDITO, R. S.; SCAGLIA, A. J. Pedagogia do Esporte. São Paulo: Phorte, 2009.

REVERDITO, R. S.; SCAGLIA, A. J.; PAES, R. R. Pedagogia do Esporte: Panorama e Análise Conceitual das Principais Abordagens. Motriz Revista de Educação Física (Impr.), Rio 
julho/2018

Claro, v. 15, n. 3, p. 600-610, 2009.

RIBAS, J. F. M. (Org.). Praxiologia Motriz e Voleibol: elementos para o trabalho pedagógico. ljuí: Unijuí, 2014.

RUFFINO, J. D. Ensenãnza del Rugby com Perspectiva Praziológica. In: RIBAS, J. F. M.

(ORG.) Praxiologia Motriz na América Latina: aportes para a didática na Educação Física. ljuí: Editora Unijuí, p. 313-320. 2017.

SALVADOR, A. D. Métodos e Técnicas de Pesquisa Bibliográfica. Porto Alegre: Sulina, 1986.

SANTOS, E. Caderno Técnico-Didático - Futebol. Brasília: Ministério da Educação e Cultura, 1979.

SCAGLIA, A. J.; REVERDITO, R. S.; GALATTI, L. Ambiente de Jogo e Ambiente de Aprendizagem no Processo de Ensino dos Jogos Esportivos Coletivos: desafios no ensino e aprendizagem dos jogos esportivos coletivos. In.: NASCIMENTO, J. V.; RAMOS, V.; TAVARES, F. (Orgs.). Jogos Desportivos: formação e investigação. Florianópolis: UDESC, 2013, p. 133-170.

SEVERINO, A. J. Metodologia do Trabalho Científico. 23. ed. São Paulo: Cortez, 2007. TAVARES, F. (Org.). Jogos Desportivos Coletivos: Ensinar a Jogar. Porto: Editora FADEUP, 2013.

TEODORESCU, L. Théorie et Méthodologie des Jeux Sportifs. Paris: Les Editeurs Français Réunis, 1977. 